\title{
Quantitative Properties of Complex Porous Materials Calculated from $\mathrm{X}$-ray $\mu \mathrm{CT}$ Images
}

\author{
Adrian P. Sheppard ${ }^{a}$, Christoph H. Arns ${ }^{a}$, Arthur Sakellariou ${ }^{a}$, Tim J. Senden ${ }^{a}$, Rob M. Sok ${ }^{a}$, Holger \\ Averdunk $^{a}$, Mohammad Saadatfar $^{a}$, Ajay Limaye $^{b}$ and Mark A. Knackstedt ${ }^{a}$ \\ ${ }^{a}$ Department of Applied Mathematics, Research School of Physical Sciences and Engineering, The \\ Australian National University, Canberra ACT 0200, Australia \\ ${ }^{b}$ VizLab, Supercomputing Facility, The Australian National University, Canberra ACT 0200, \\ Australia
}

\begin{abstract}
A microcomputed tomography $(\mu \mathrm{CT})$ facility and computational infrastructure developed at the Department of Applied Mathematics at the Australian National University is described. The current experimental facility is capable of acquiring 3D images made up of $2000^{3}$ voxels on porous specimens up to $60 \mathrm{~mm}$ diameter with resolutions down to $2 \mu \mathrm{m}$. This allows the three-dimensional (3D) pore-space of porous specimens to be imaged over several orders of magnitude. The computational infrastructure includes the establishment of optimised and distributed memory parallel algorithms for image reconstruction, novel phase identification, 3D visualisation, structural characterisation and prediction of mechanical and transport properties directly from digitised tomographic images.

To date over 300 porous specimens exhibiting a wide variety of microstructure have been imaged and analysed. In this paper, analysis of a small set of porous rock specimens with structure ranging from unconsolidated sands to complex carbonates are illustrated. Computations made directly on the digitised tomographic images have been compared to laboratory measurements. The results are in excellent agreement. Additionally, local flow, diffusive and mechanical properties can be numerically derived from solutions of the relevant physical equations on the complex geometries; an experimentally intractable problem. Structural analysis of data sets includes grain and pore partitioning of the images. Local granular partitioning yields over 70,000 grains from a single image. Conventional grain size, shape and connectivity parameters are derived. The 3D organisation of grains can help in correlating grain size, shape and orientation to resultant physical properties. Pore network models generated from 3D images yield over 100000 pores and 200000 throats; comparing the pore structure for the different specimens illustrates the varied topology and geometry observed in porous rocks. This development foreshadows a new numerical laboratory approach to the study of complex porous materials.
\end{abstract}

Keywords: X-ray micro-tomography, porous media, quantitative calculations, transport and mechanical properties, grain partitioning and analysis

\section{INTRODUCTION}

An X-ray microcomputed tomography facility was commissioned to study the effect of morphology and geometry on mechanical and transport properties of real world biological, geological and synthetic materials. Many analytical tools have been developed to probe these relationships, including technologies to visualise, characterise and predict material properties from three-dimensional images of microstructure. In this section, the acquisition hardware, the reconstruction software and the necessary post-processing software are introduced.

Further author information: (Send correspondence to M. A. Knackstedt)

M. A. Knackstedt: E-mail: mark.knackstedt@anu.edu.au, Telephone: 61 (0)2 61253357

A. P. Sheppard: E-mail: adrian.sheppard@ anu.edu.au, Telephone: 61 (0)2 61258516

C. H. Arns: Email: christoph.arns@anu.edu.au, Telephone: 61 (0)2 61255170

Developments in X-Ray Tomography $\mathrm{V}$, edited by Ulrich Bonse,

Proc. of SPIE Vol. 6318, 631811, (2006) -1605-7422/06/\$15 · doi: 10.1117/12.679205

Proc. of SPIE Vol. $6318631811-1$ 


\subsection{Hardware}

The imaging technique of "tomography" generates a data set, called a tomogram, which is a three dimensional representation of the structure and variation of X-ray attenuation within a specimen. Each three dimensional point in the tomogram is called a voxel. The X-ray $\mu \mathrm{CT}$ instrument at this facility was designed to probe many length scales simultaneously, with a large field of view $\left(2048^{3}\right.$ voxels and $60 \mathrm{~mm}$ cross-section), high spatial resolution $(2 \mu \mathrm{m})$, high dynamic range for enhanced contrast (16 bits), tunable geometric magnification between $\times 1.1$ to $\times 100$, sufficient throughput to permit slow time series experiments and with ample versatility to implement and develop various contrast enhancing and in situ imaging techniques. The instrument, ${ }^{1,2}$ shown in figure 1 , is housed in a lead shielded room. To image a specimen, the $\mathrm{X}$-ray camera records a set of transmission radiographs at different views by rotating the specimen. Due to the geometry of the X-ray beam, the specimen is rotated through 360 degrees. To generate a tomogram, these radiographs are processed with a reconstruction algorithm. The following is a brief description of the three main components:

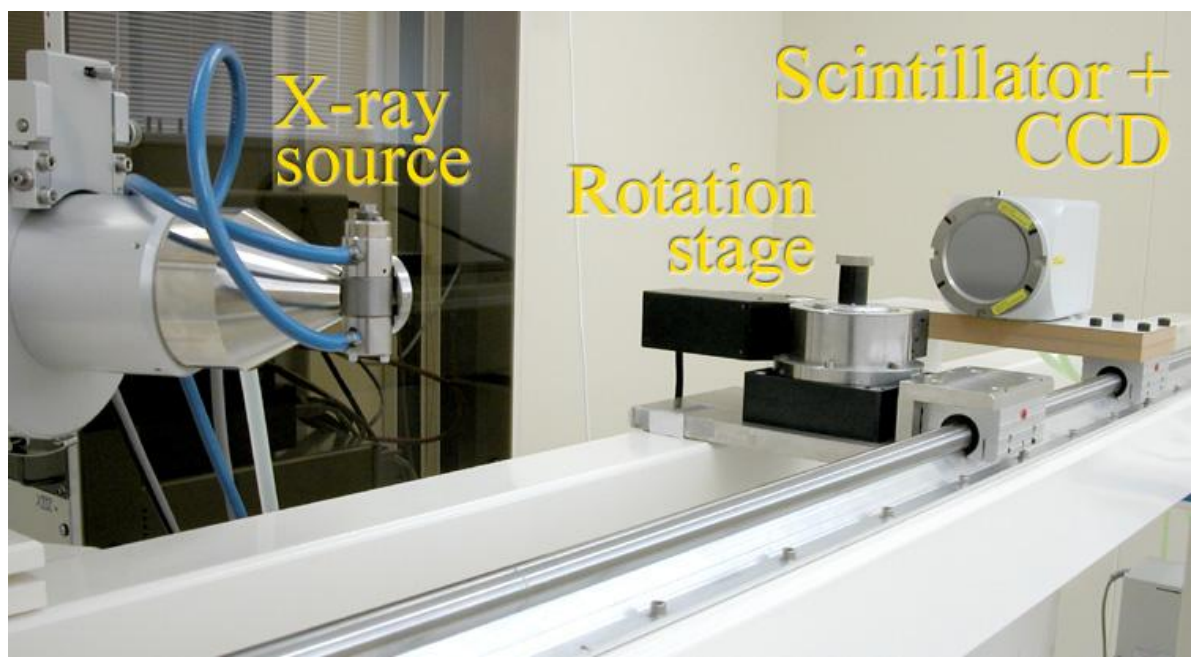

Figure 1. A photo of the X-ray tomography instrument.

X-ray Source: An X-Tek (UK) RTR-UF225/0 continuously pumped X-ray gun is used as the X-ray source. It has high precision electron beam optics which produces a superior brilliance and finer focus of the X-ray beam. The electron beam can be set to a voltage of $225 \mathrm{kV}$ (typical setting $80 \mathrm{kV}$ ) and a current of $2 \mathrm{~mA}$ (typical setting $0.2 \mathrm{~mA}$ ) and can be focussed down to a spot size of 2-5 $\mu \mathrm{m}$. The target is typically tungsten, thus generating polychromatic X-rays via bremsstrahlung.

Rotation Stage: A Newport RV120 rotation stage is used to rotate the specimen during data collection and has a precision of 1 milli-degree. It is capable of supporting large axial loads of up to $120 \mathrm{~kg}$. It has a central aperture, allowing in situ experimental apparatus to rotate suspended underneath the specimen during an experiment.

X-ray Camera: A Roper PI-SCX100:2048 X-ray camera was specifically designed for the facility. Hermetically sealed behind a $0.5 \mathrm{~mm}$ Be window, a scintillator made from $140 \mu \mathrm{m}$ thick CsI(Tl) hexagonal crystal with High Reflective coating is grown directly onto a tapered fibre optic bundle which efficiently channels the light directly onto a CCD for image formation. The CCD is a $2084 \times 2084$ pixel Grade 1 , Kodak KAF4302E and is Peltier cooled to $-50{ }^{\circ} \mathrm{C}$. The image is retrieved from the CCD with two 16-bit ADCs capable of 1 MegaPixel per second readout. The pixel pitch of the CCD is $24 \mu \mathrm{m}$ and coupled with a magnification of 1.4 in the tapered fibre optic bundle, the X-ray camera has an active area of $70 \times 70 \mathrm{~mm}$.

\subsection{Software Reconstruction}

The main characteristics of this facility is that the source produces a polychromatic X-ray beam and the radiograph data are collected with a cone beam along a circular trajectory. Even though such characteristics are less than ideal and potentially problematic for tomography, high quality and accurate tomograms are generated.

The effects of a polychromatic X-ray beam are minimised by choosing a filter with the same composition as the major constituent in the specimen and with a thickness about $25-50 \%$ the diameter of the specimen. This helps to avoid issues 
associated with beam hardening artifacts. A cone beam with a circular trajectory has the potential for a shadow zone in which no information, in the Fourier domain, can be collected. For there to be significant frequency information in the shadow zone, the specimen must consist of a periodic distribution of parallel planar edges, in which their normals are aligned parallel to the rotation axis. Fortunately, in the analysis of porous media, specimens do not have such structure. Even if they did, the specimen can simply be imaged by rotating the specimen perpendicular rather than parallel to the normal of these edges.

The tomogram is generated by applying the Feldkamp algorithm ${ }^{3}$ to the radiographs. However, the Feldkamp algorithm only works if many assumptions about the quality and alignment of the radiographs are satisfied. Therefore, most effort in generating a tomogram is not in the reconstruction but is in the development of robust pre-processing algorithms that adequately remove experimental limitations from the radiographs. Without going into details, the main steps employed are:

- Correction for image distortion due to the spatial non-linearity of the X-ray camera. The distortion is caused by the process to manufacture the tapered fibre optic bundle.

- Linearisation of the X-ray yield to compensate for the non-linear interaction of X-rays with matter.

- Normalisation of the X-ray yield to remove any fluctuations in the X-ray intensity.

- Removal of any detected cosmic rays.

- Removal of persistent pixel defects in the X-ray camera so as to minimise ring artifacts in the tomogram. The predominate defects are due to irregularities in the tapered fibre optic bundle.

- Correction for any geometric misalignment between the source, specimen and detector. The amount of misalignment is measured and is corrected by mapping each radiograph from a physical plane to a virtual plane. The virtual plane adheres to the strict geometric requirements of the Feldkamp algorithm.

\subsection{Phase Separation}

The tomogram consists of a cubic array of reconstructed linear x-ray attenuation coefficient values, each corresponding to a finite volume cube (voxel) of the specimen. An immediate goal is to differentiate the attenuation map into distinct pore and grain phases for each of the specimens imaged. Ideally one would wish to have a clear bimodal (or multimodal, in the case of specimens made up of more than one material) distribution separating the pore phase from mineral phase peaks. This simple phase extraction is possible on, for example, clean sandstone specimens, where the mineralogy is simple.

In more complex specimens, and in particular carbonates, three-phase (or more) identification is required. Unfortunately the presence of pores at scales below the tomogram resolution leads to a spread in the low density signal making it difficult to unambiguously differentiate the resolvable pore phase, the intermediate microporous phase and the dense solid phase. To quantitatively analyse tomograms, a well-defined and consistent method to label each voxel has been developed. ${ }^{4}$ The first stage comprises a nonlinear anisotropic diffusion (AD) filter ${ }^{5}$ which removes noise while preserving significant features, i.e. the boundary regions between the phases. The second stage applies an unsharp mask (UM) sharpening filter ${ }^{6}$ which has proven itself in practice to be highly effective at sharpening edges without overly exaggerating the noise. Finally, the phase separation is performed using a combination of watershed ${ }^{7}$ and active contour methods. ${ }^{8}$ This method, that we call Converging Active Contours, has been implemented in parallel using a novel algorithm, to enable the segmentation of full size tomograms.

\subsection{D Visualisation}

Drishti, a volume rendering program that directly uses hardware-accelerated graphics primitives, has been developed. Facility users visualise their data sets interactively. The software allows for real-time sculpting of the volumetric data to expose the internal structure. Drishti allows splicing of the data as well as making movies of the data sets, and can be operated in stereo mode when displaying through suitable hardware. Drishti runs on current workstations with graphics capabilities supporting 3D textures. A screen shot is provided in figure 2. Various examples of movies are available at: http: //xct.anu.edu.au. 


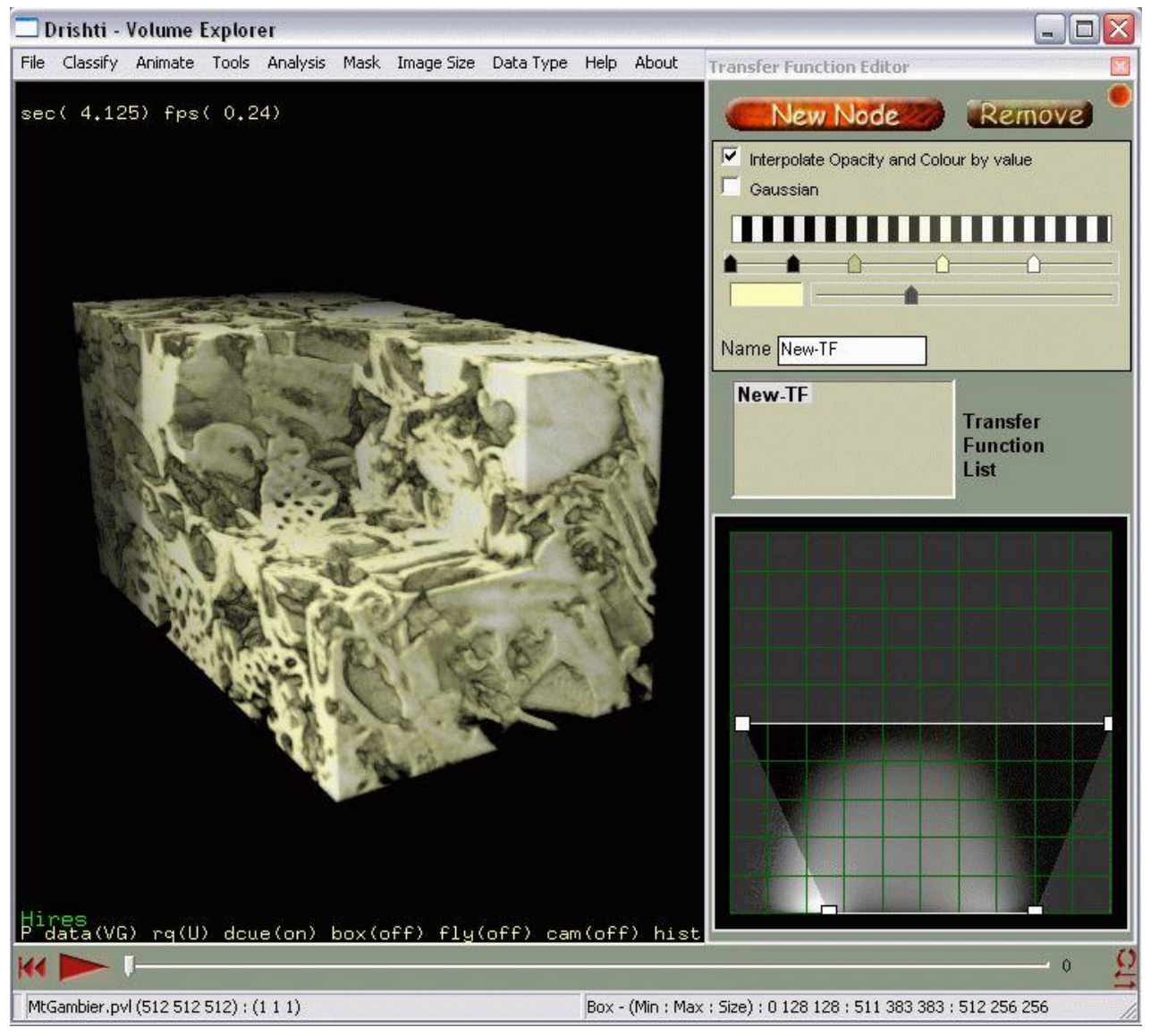

Figure 2. The Drishti volume rendering software used to visualise 3D volume data. In this screen shot, a small subset of the "Outcrop" specimen is shown.

\section{TOMOGRAM DATA}

Studies on a number of porous rock specimens are described in this paper. These specimens range from a simple monodisperse granular pack, one unconsolidated sandstone, two consolidated sandstones of varying complexity, two model dualscale specimens (supplied by Marios Ioannidis), and two complex carbonate specimens. While sandstones are made up of simple granular building blocks and a dominant pore size, carbonate rocks often have a bi- or tri-modal pore size distribution with organisms playing an important role in forming the reservoirs. Carbonate rocks are further complicated by the significant diagenesis occurring through chemical dissolution, reprecipitation, dolomitization, fracturing, etc. We choose one outcrop (young) carbonate specimen and a second that has undergone extensive diagenesis. Examples of transverse cross-sections of the tomograms for each of the specimens are given in figure 3. Details of the experimental measurement, voxel size and resultant tomogram porosity are given in table 1 .

\subsection{Pore Phase Identification}

The phase identification process for the "Unconsolidated" specimen, which is a clean simple sandstone, and the "Complex" specimen, which exhibits extensive unresolved microporosity is briefly described. The intensity histogram for both specimens are given in figure 4. Segmentation was performed on the sandstone specimen assuming absolute thresholds of $\leq 5100$ for the pore phase and $\geq 7500$ for the solid phase and for the carbonate specimen assuming absolute thresholds of $\leq 18000$ for the pore phase and $\geq 22000$ for the solid phase. Phase separation in the ambiguous intensity regions between these phases was then made using the Converging Active Contours algorithm. The resultant segmented tomograms are shown in figure 4 . The calculated phase fraction obtained for the sandstone tomogram was $\phi_{\text {tomo }}=36.7 \%$ and for the carbonate tomogram was $\phi_{\text {tomo }}=18.5 \%$. 
[a]

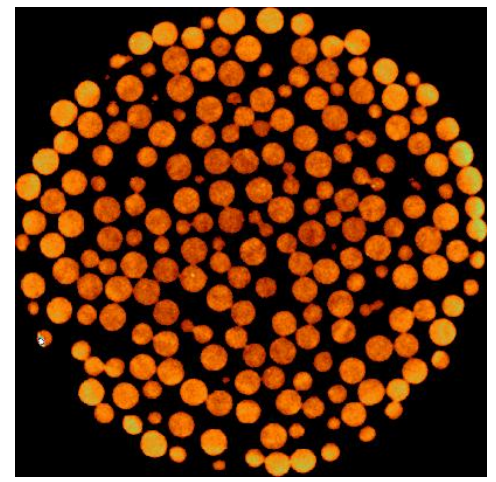

[b]

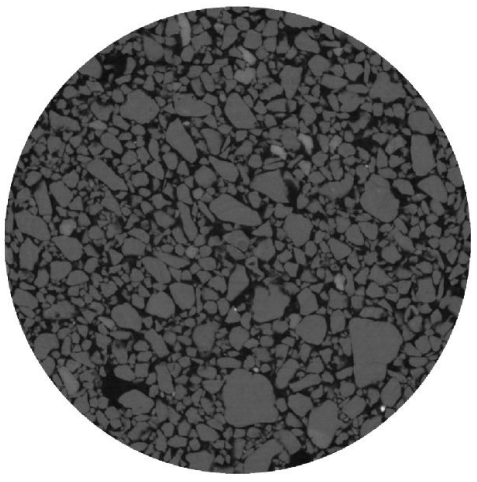

[c]

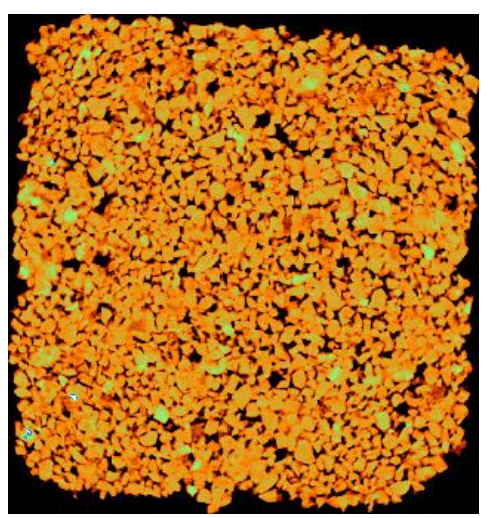

[e]

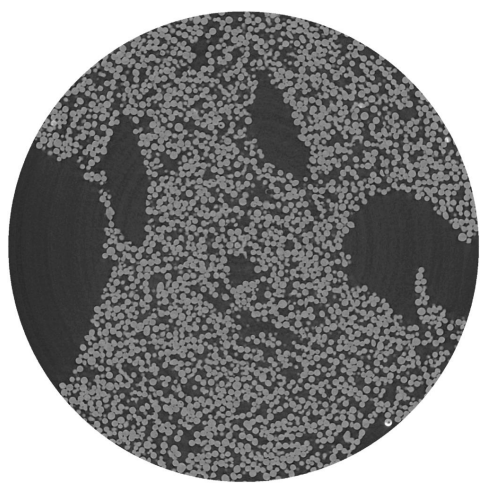

[f]

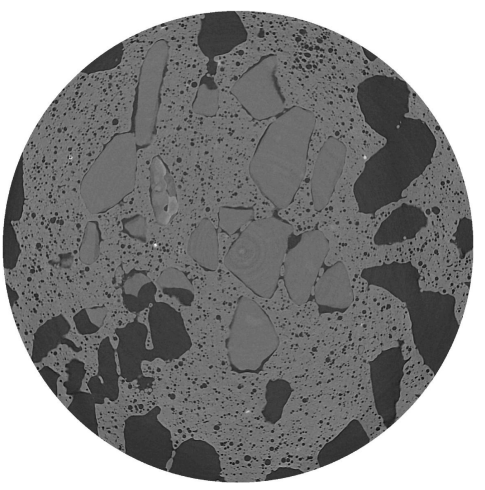

[g]

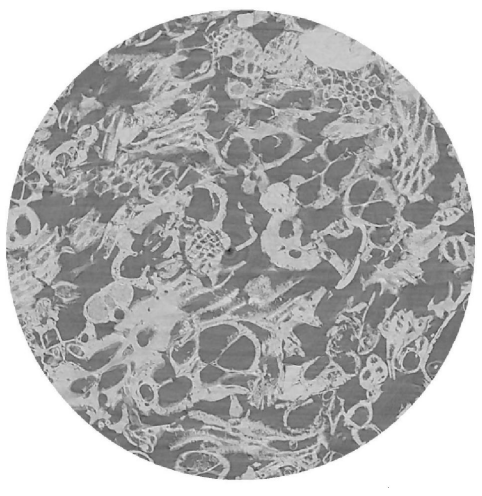

[h]

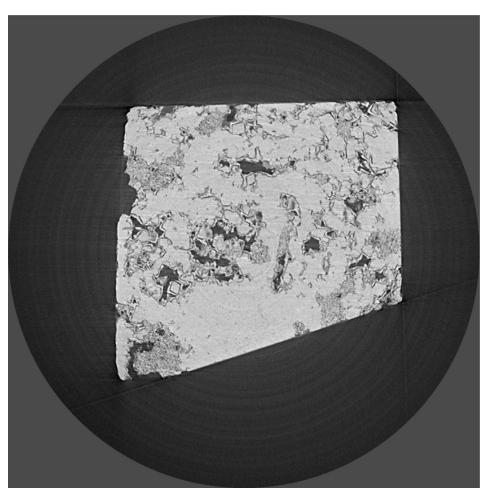

Figure 3. Transverse cross-sections of the specimens considered in this study: (a) "Grain Pack" (b) "Unconsolidated" (c) "Consolidated 1" (d) "Consolidated 2" (e) "Dual 1" (f) "Dual 2" (g) "Outcrop" (h) "Complex" 


\begin{tabular}{|l|c|c|c|c|}
\hline Specimen & Type & Voxel & Tomogram & $\phi_{\text {tomo }}$ \\
\hline \hline Grain Pack & artificial & 63.43 & $2000^{3}$ & $54.0 \%$ \\
Unconsolidated & sandstone & 9.42 & $2000^{3}$ & $36.7 \%$ \\
Consolidated 1 & sandstone & 5.87 & $2000^{3}$ & $28.1 \%$ \\
Consolidated 2 & sandstone & 4.50 & $2000^{3}$ & $21.8 \%$ \\
Dual 1 & artificial & 4.93 & $2000^{3}$ & $53.2 \%$ \\
Dual 2 & artificial & 4.89 & $2000^{3}$ & $28.8 \%$ \\
Outcrop & carbonate & 3.06 & $2000^{3}$ & $51.3 \%$ \\
Complex & carbonate & 2.6 & $2000^{3}$ & $18.5 \%$ \\
\hline
\end{tabular}

Table 1. Details of the specimen type, voxel size $(\mu \mathrm{m})$, tomogram size (voxels) and tomogram porosity $\phi_{\text {tomo }}$ for the specimens considered in this paper.

[a]

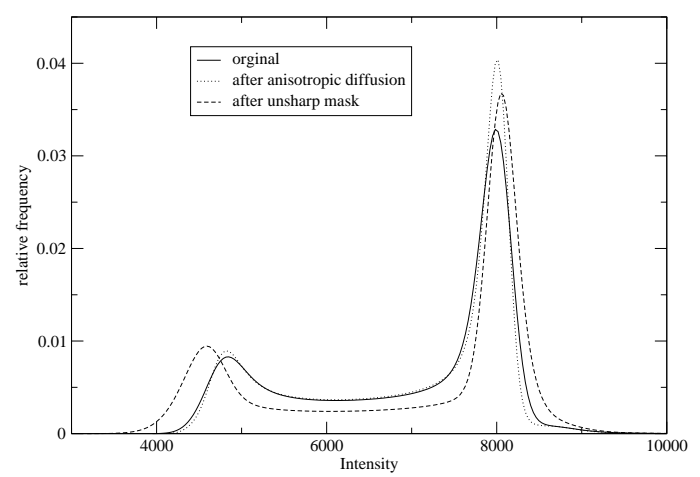

[c]

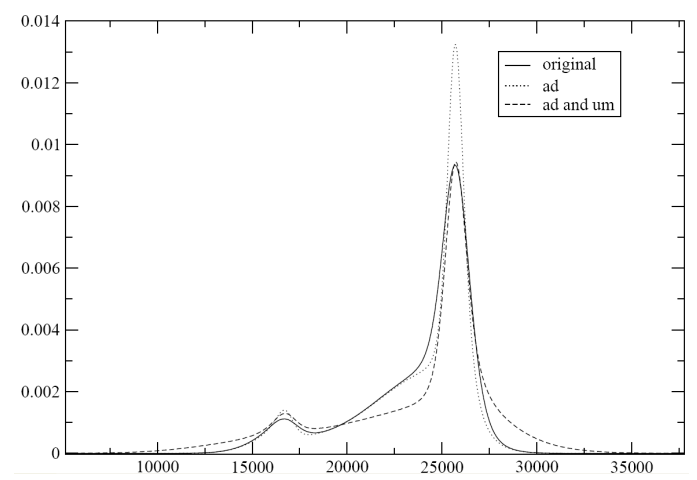

[b]

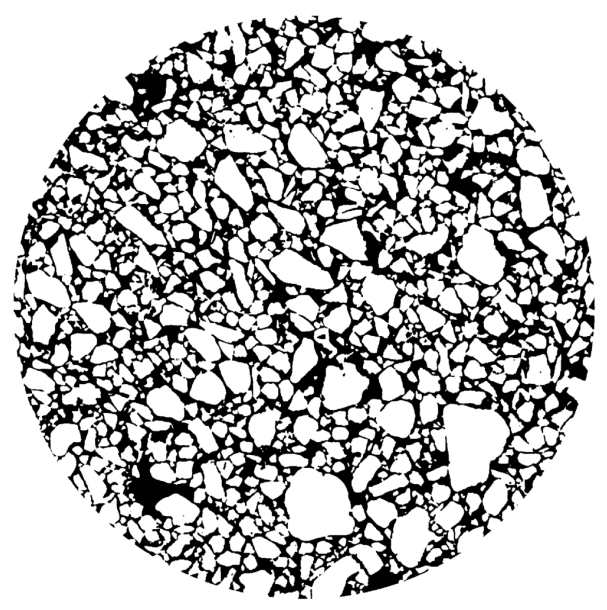

[d]

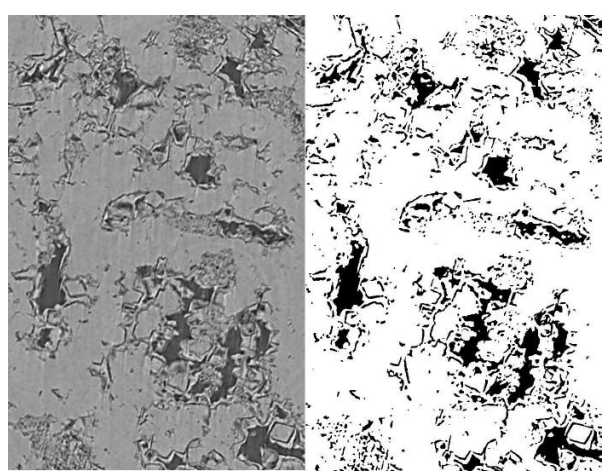

Figure 4. (a) Attenuation distribution of the "Unconsolidated" specimen showing a clear distinction between pore and mineral phases before and after application of anisotropic diffusion and unsharp mask filtering; (b) The resultant segmented tomogram of the crosssection shown in figure 3(b). (c) The attenuation distribution for the "Complex" specimen; (d) The resultant segmented tomogram, compared to the original tomogram. 


\subsection{Tomogram Quality: Match to MICP data}

A quality control step on the tomogram is undertaken by comparing a mercury invasion capillary pressure (MICP) measurement on the imaged specimen to simulations of MICP undertaken directly on the segmented tomogram pore phase volume. Simulations of MICP result in a capillary pressure $\left(P_{c}\right)$ vs. saturation $(S)$ curve for the tomogram. There are a few similar techniques to calculate these curves ${ }^{9-11}$ amongst which our implementation results in faster calculations. ${ }^{11}$ In short, drainage simulations are performed directly on a segmented tomogram by carrying out a percolation test of the subset of Euclidean distance map ${ }^{12}$ for which the radius is larger than the invasion radius considered. The saturation of the invading fluid at that pressure is given by the dilation of this "burned" cluster with the invading sphere size. At a fixed capillary pressure (pore entry radius), all the spheres which have radius greater than or equal to the equivalent pore entry radius are considered. Starting with the largest sphere and incrementing the sphere radius downwards (equivalent to incrementing capillary pressure upwards), the non-wetting phase saturation is measured as the subset of all spheres that have invaded the pore space. The resultant $\left(P_{c}\right)$ vs. $(S)$ curve is directly compared to experimental MICP data on the same specimen. In figure 5, four examples of the experimental vs. calculated data are shown for the "Dual 1", "Dual 2", "Outcrop" and "Complex" specimens. In all cases good agreement between the experimental and the tomogram based result are observed. In the first three cases the numerical fit to the experimental curve is good across the full saturation range. In the fourth specimen, due to the presence of a significant fraction of microporosity (pores $\leq 4 \mu \mathrm{m}$ ), there is a cut-off at intermediate saturations. The simulation cannot replicate the full curve due to the inability to image pore sizes below tomogram resolution. Up to the intermediate saturation the experimental and numerically derived MICP results are in reasonable agreement.

\section{STRUCTURAL CHARACTERISATION}

\subsection{Grain Partitioning}

Descriptions of grain size, shape and organisation are of great interest as they can be used in classifying rock types and in the interpretation of the environment of rock deposition. Grain shape and size information is further used to correlate to transport and mechanical properties. Descriptions of granular media and sedimentary rocks are traditionally obtained via micrographic and analytical techniques including thin section analysis, ${ }^{13}$ particle sieving techniques ${ }^{14,15}$ and laser diffraction studies. ${ }^{16}$ All methods have obvious limitations in quantitatively describing the full 3D granular structure. Traditional analytical techniques require the bulk material to be dispersed from its original form. Dispersion destroys a range of granular scale information of significant value to the resultant material properties; information on particle orientation, density variations and spatial correlations is lost. It is only with tomography that the 3D organisation of grains is captured!

In short, individual grains are identified within the grain space using a similar approach to that used by Thompson et al, ${ }^{17}$ and an extended version of the technique that we have previously described. ${ }^{18}$ Euclidean distance and covering radius transforms are calculated. Next, grain centres are identified as those voxels that aren't covered by a larger radius in the covering radius map, as defined by morphological opening operations. ${ }^{10}$ These centres are used to seed a watershed transform based on the Euclidean distance map, which partitions the grain space into regions whose boundaries coincide with constrictions of the grain space. To overcome the over-partitioning that seems inevitable with these methods, a carefully designed region-merging algorithm ${ }^{19}$ is applied to the watershed partitioning to remove spurious grains. We have shown that a single tomogram can yield more than 70,000 individual grains. This allows one to characterise the individual grains including grain size and shape along with other morphological information (sorting, grain contacts, matrix/grain support). This analysis is particularly relevant for sandstone data sets, which often correspond closely to granular packings. Transverse cross-sections illustrating the grain partitioning of the "Grain Pack", "Unconsolidated", "Consolidated 1" and "Consolidated 2" specimens are shown in figure 6. From visual inspection, the partitioning looks realistic. A threedimensional example of grain partitioning of a small subset of the "Consolidated 1" specimen is shown in figure 7.

A comparison of grain size analysis from tomograms to experimental data is undertaken on the "Grain Pack" and "Unconsolidated" specimens. The measured grain size distribution from the tomogram of the monodisperse "Grain Pack" specimen leads to a prediction of a mean grain diameter of $2.98 \mathrm{~mm}$. The bead diameter given by the manufacturer is $3 \mathrm{~mm}$. This variation is acceptable as it is of the order of less than a single voxel. For the "Unconsolidated" specimen, laser diffraction studies on sister material were undertaken; good agreement between estimates of grain size is obtained (figure 8). 

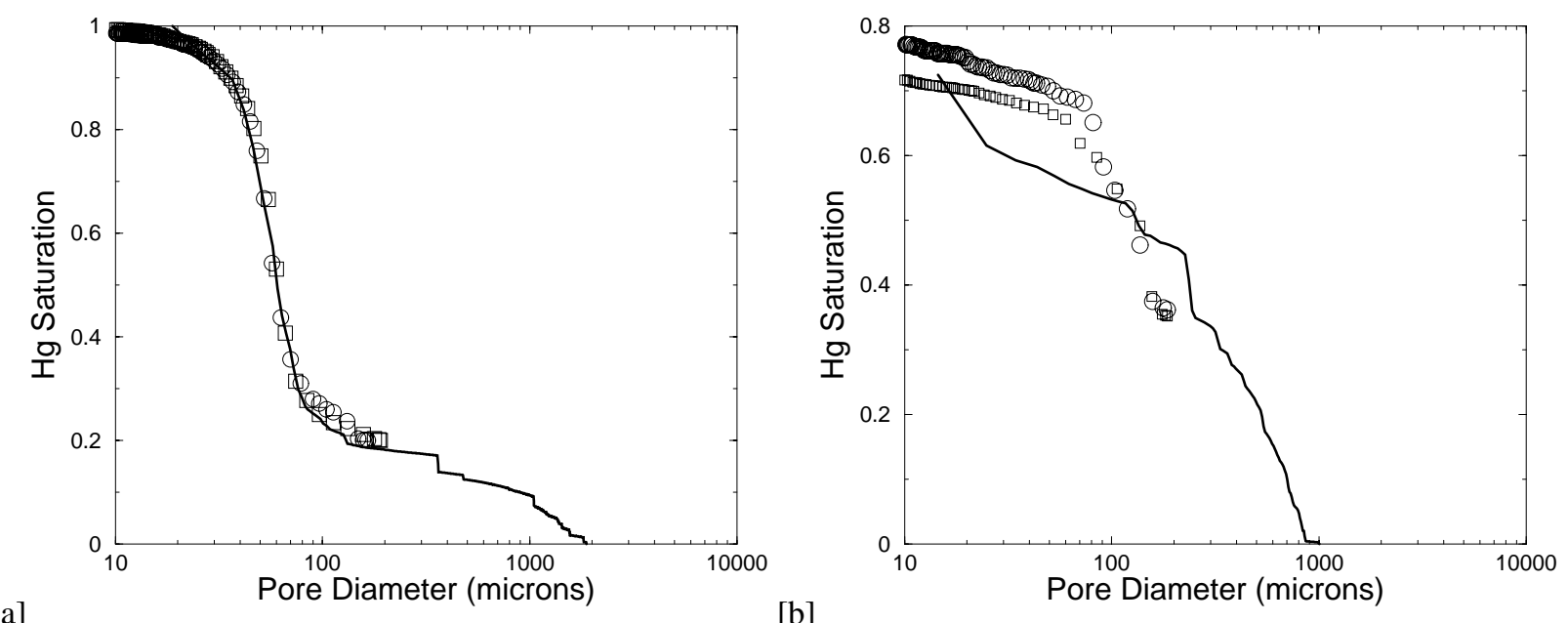

[a]

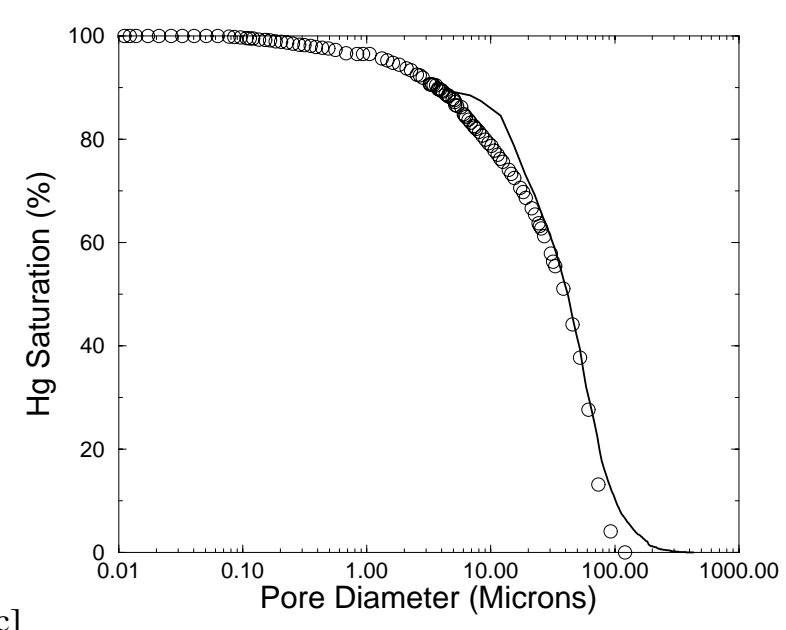

[c]

$[\mathrm{d}]$ [b]

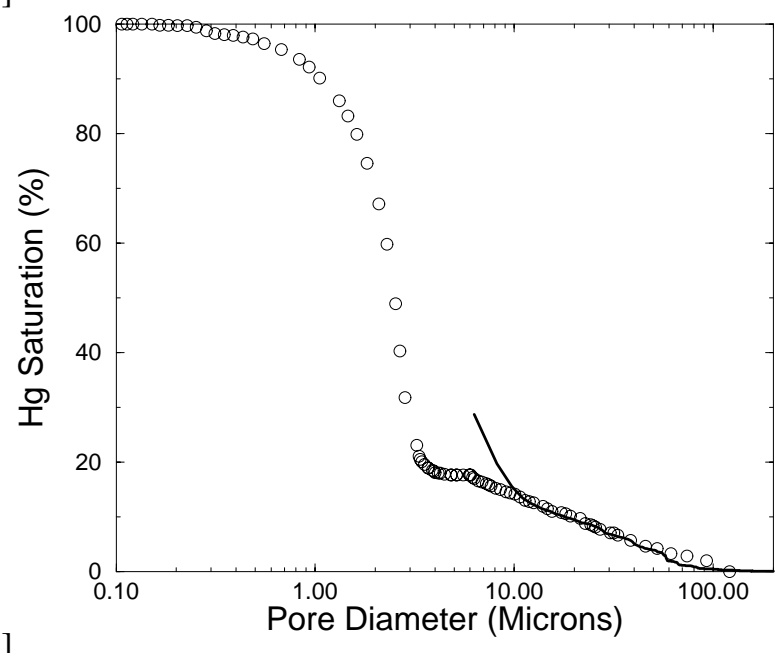

Figure 5. Comparison of tomogram based MICP calculations to direct MICP measurement on the same (a) "Dual 1", (b) "Dual 2", (c) "Outcrop" and (b) "Complex" specimens. Legend: Solid line are calculated results and, in this case, the "circles" and "squares" are measurements done on different pieces of the same specimen. 

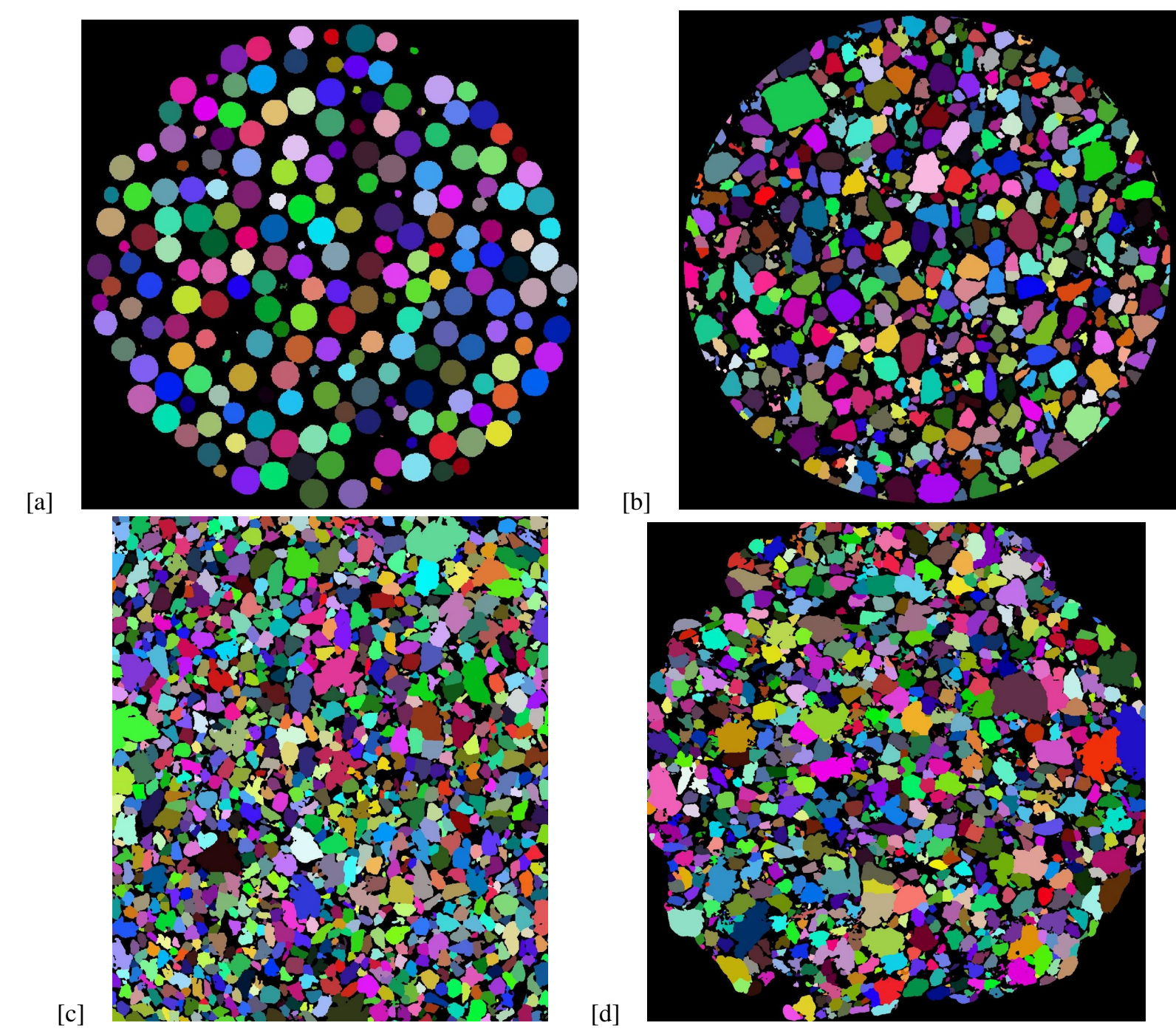

Figure 6. Transverse cross-sections of the partitioned tomogram of the (a) "Grain Pack", (b) "Unconsolidated", (c) "Consolidated 1" and (d) "Consolidated 2" specimens. From visual inspection the grain partitioning seems realistic. 


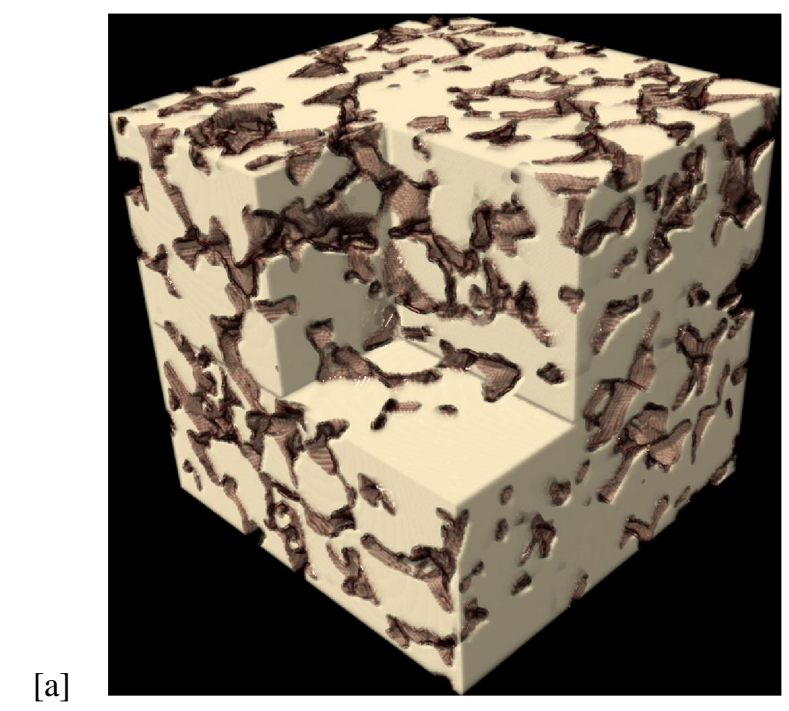

[b]

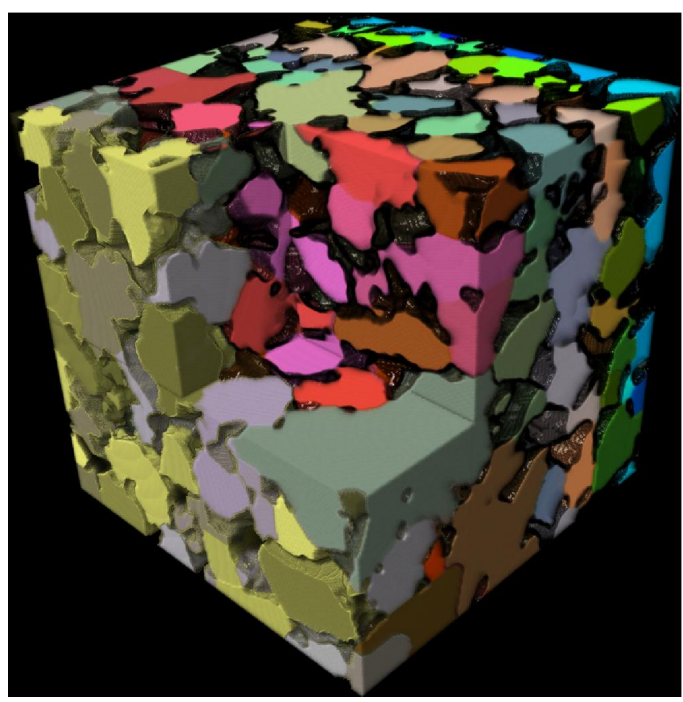

Figure 7. Demonstration of the grain partitioning algorithm on a small 3D subset of the "Consolidated 1" tomogram.

[a]

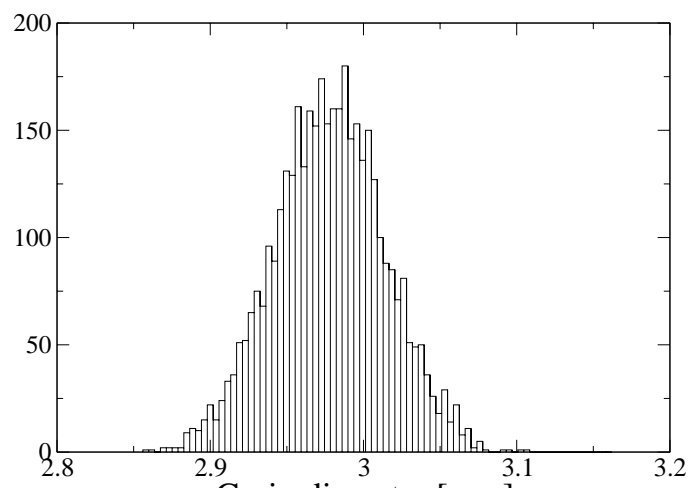

Grain diameter $[\mathrm{mm}]$

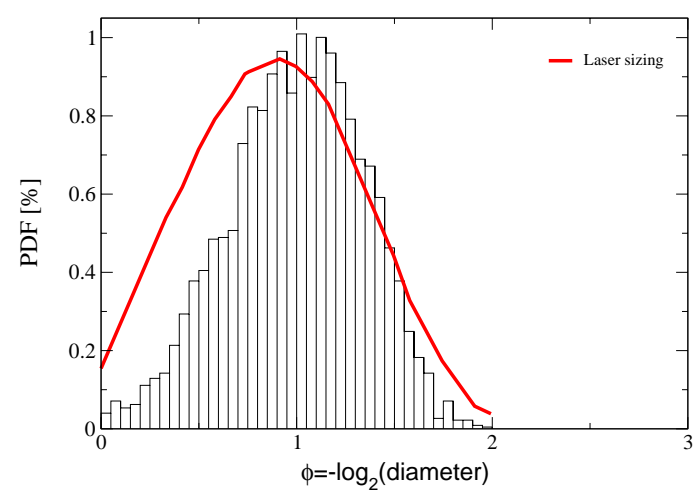

Figure 8. (a) Grain size distribution for the monodisperse "Grain Pack" specimen; bead diameter given by manufacturer was $3 \mathrm{~mm}$. (b) Comparison of the grain size distribution obtained from tomogram to laser particle sizing on a different piece of the same specimen, for the "Unconsolidated" specimen. 
Data obtained over thousands of grains allows one to obtain comprehensive granular size and shape statistics. In table 2, grain size distribution information (mean, median, standard deviation, skewness) and grain shape statistics (roundness, aspect ratio) for the full ensemble of grains in the "Grain Pack", "Unconsolidated", "Consolidated 1" and "Consolidated 2" specimens are detailed. Grain pack connectivity and grain overlap is summarised in table 2 and figure 9. Measures of grain contacts and grain overlap area show that many grains are singly connected while others are in contact with more than 20 other grains. The two consolidated specimens have significantly more grain overlap area than the corresponding grain pack and unconsolidated specimens.

\begin{tabular}{|c|c|c|c|c|c|c|c|c|}
\hline Specimen & No. & Mean & Median & SD & SK & $Z$ & $Z_{\text {med }}$ & $Z_{w}$ \\
\hline \hline Grain Pack & 4524 & 2.98 & 2.98 & 0.018 & 0.040 & 5.18 & 9 & 5.18 \\
Unconsolidated & 28649 & 1.85 & 1.90 & 0.37 & -0.09 & 5.63 & 5 & 10.58 \\
Consolidated 1 & 65492 & 2.83 & 2.76 & 0.56 & 0.36 & 10.26 & 10 & 14.12 \\
Consolidated 2 & 29089 & 3.06 & 2.76 & 1.21 & 0.33 & 7.47 & 6 & 18.65 \\
\hline
\end{tabular}

Table 2. For each specimen listed, the following parameters are reported: The number of grains captured in the tomogram (No.). The mean volume of the grain (Mean) in $\mathrm{mm}$. The median size of the grain (Median) in $\mathrm{mm}$. The sorting or standard deviation (SD) and the skewness (SK) of the grain size distribution, in units of $\Phi=-\log _{2}[D(\mathrm{~mm})]$. The average $(Z)$, median $\left(Z_{m e d}\right)$ and volume weighted $\left(\bar{Z}_{w}\right)$ connectivity.

[a]

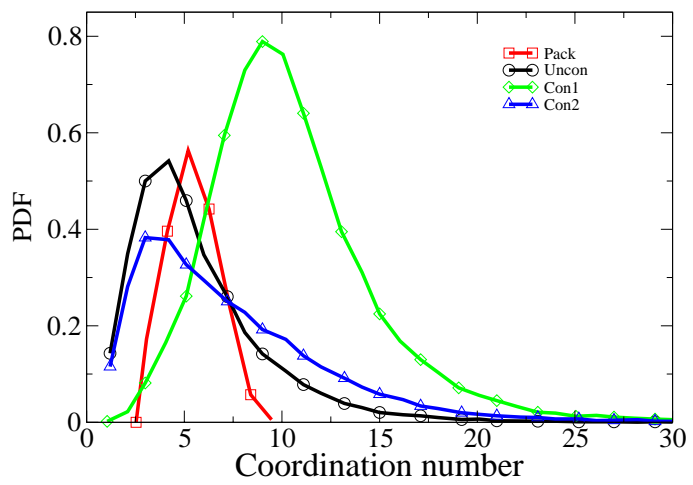

[c]

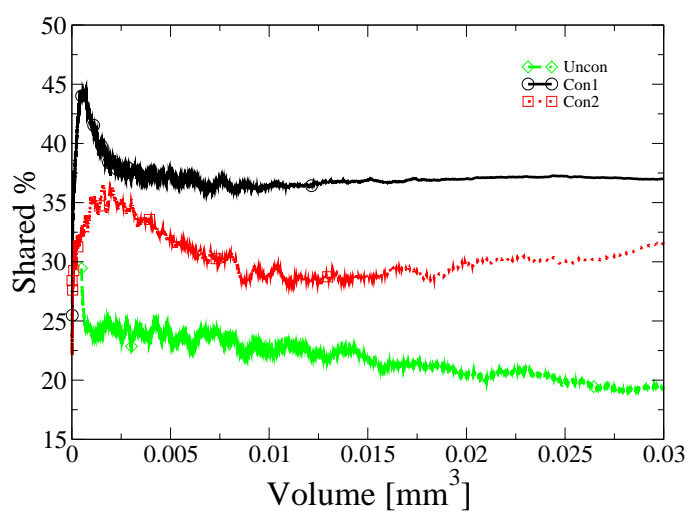

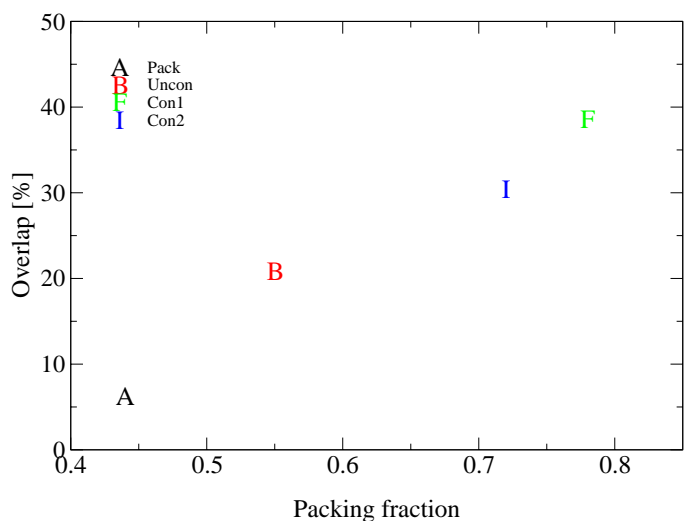

[b]

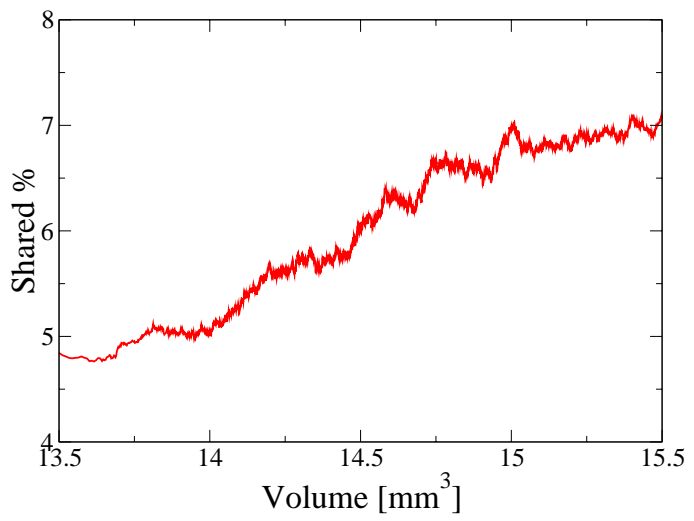

Figure 9. (a) Probability distribution of the coordination number of the four specimens. (b) Average value of the grain overlap in percentile as a function of the grain packing fraction. (c) The fraction of grain surface shared with neighbouring grains for the 3 sandstone specimens. (d) The same plot as (c) for the monodisperse grain pack. 


\subsection{Pore Partitioning}

Pore network models are considered as practical pore space description and simulation tools. The guiding idea is that the pore space can be naturally discretised into subvolumes separated at the locally narrowest constrictions. The subvolumes and the constrictions can then be identified with the nodes (pore bodies) and links (pore throats) of a network. To date network descriptions used for the study of flow properties have been primarily based on idealised (lattice-based) networks or are generated by stochastic realizations based on thin section data. The algorithm that we have developed to generate representative pore-throat networks has been described in. ${ }^{19}$ Here we show that the generation of networks directly from a range of segmented tomograms leads to a strongly varying topology and pore geometry exhibited by different rock types. In figure 10, 4 images of networks derived from the tomograms of the "Consolidated 1", "Dual 2", "Outcrop" and "Complex" specimens are shown. The difference in the network structure for these four specimens is dramatic. From the networks a number of important parameters can be ascertained; two of the more important parameters is the coordination number of the pores in the network $(Z)$ and the aspect ratio of the pore radii $\left(r_{p}\right)$ to the throat radii $\left(r_{t}\right)$. Mean data and data weighted by pore volumes are given in table 3 . Despite the varying topology, $\left(Z_{\text {mean }}\right)$ of the "Consolidated 1" and "Outcrop" specimens are similar, while the "Complex" specimen is on average lower. The weighted coordination number is much larger for both carbonates reflecting the strong interconnectivity of the larger pores. The aspect ratio of all non-sandstone systems is significantly larger than the sandstone on both a mean and weighted scale. The volume weighted average again highlights the large aspect ratio exhibited by the larger pores, which may in turn dominate the multiphase flow properties. ${ }^{20}$

\begin{tabular}{|l|c|c|c|c|c|c|c|}
\hline Specimen & $N_{t}$ & $N_{p}$ & $Z_{\text {mean }}$ & $Z_{\text {weight }}$ & $Z_{\text {max }}$ & $\frac{R_{p}}{R_{t}}$ mean & $\frac{R_{p}}{R_{t} \text { weight }}$ \\
\hline \hline Consolidated 1 & 272422 & 102682 & 5.4 & 9.0 & 49 & 2.9 & 4.0 \\
Dual 2 & 83047 & 46171 & 3.6 & 31.4 & 227 & 3.0 & 30.3 \\
Outcrop & 149055 & 51333 & 5.6 & 30.4 & 372 & 6.5 & 20.3 \\
Complex & 131245 & 67863 & 3.8 & 35.0 & 276 & 3.4 & 28.0 \\
\hline
\end{tabular}

Table 3. Details of the four network structures shown in figure 10. $N_{t}$ and $N_{p}$ give the numbers of throats and pores within each tomogram.

\section{PHYSICAL PROPERTIES}

A microstructure defined by a segmented tomogram is already discretised and lends itself immediately to numerical computation of a range of physical properties. We have described previously ${ }^{2}$ the techniques used to calculate fluid flow, ${ }^{21}$ conductivity, ${ }^{22}$ diffusivity ${ }^{23}$ and elastic ${ }^{24}$ properties. One may also obtain local-scale information ${ }^{25,26}$ which cannot be measured experimentally; for example in figure 11, local flow paths within a porous structure are illustrated. The flow in the well connected "Consolidated 1" specimen is characterised by many parallel flow paths all contributing to the overall flux within the pores. In contrast the flow through the "Complex" specimen is characterised by a single dominant flow path, made up of the most open connected porous pathway. This information will help in understanding the fluid mixing properties of a range of sedimentary material; this is of great importance in the understanding of contaminant flow in the sub-surface and the potential for cleaning up these sites. Other properties (e.g, local conductive properties, local stress and strain) can be derived locally from solutions to the conductivity and elastic properties on the tomogram.

\section{CONCLUSION}

The developments described in this paper foreshadow a new numerical laboratory approach to the study of complex porous materials. Tomograms of complex porous materials are obtained at pore scale resolution. The quality of tomograms are tested by direct comparison between experimental MICP measurements on the specimen and numerical MICP tests on the tomogram. We have shown that microtomographic imaging coupled with computational techniques have now progressed to the point where structural properties at a local scale such as grain size and shape, pore size and shape and coordination of the solid and granular phases can be directly measured in 3D. We have also shown that diffusivity, elasticity, permeability and conductivity can be calculated directly on large tomograms of porous materials in agreement with experiment and that local scale flow, elastic and diffusion information can also be derived from numerical simulation on segmented tomograms. Microtomographic imaging at higher resolutions with faster acquisition times will allow dynamical effects to be studied. The continued parallel development of these experimental and computational methods should lead to the ability to image 


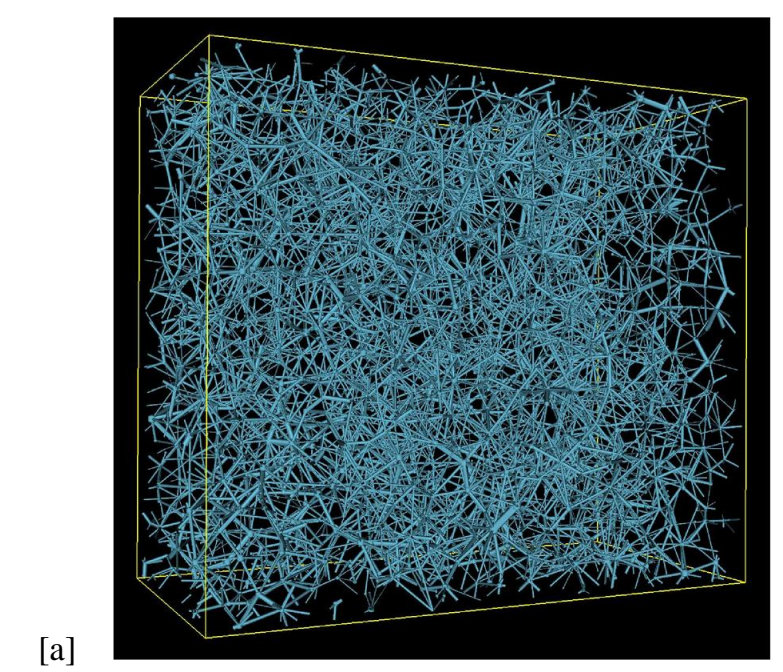

[a]

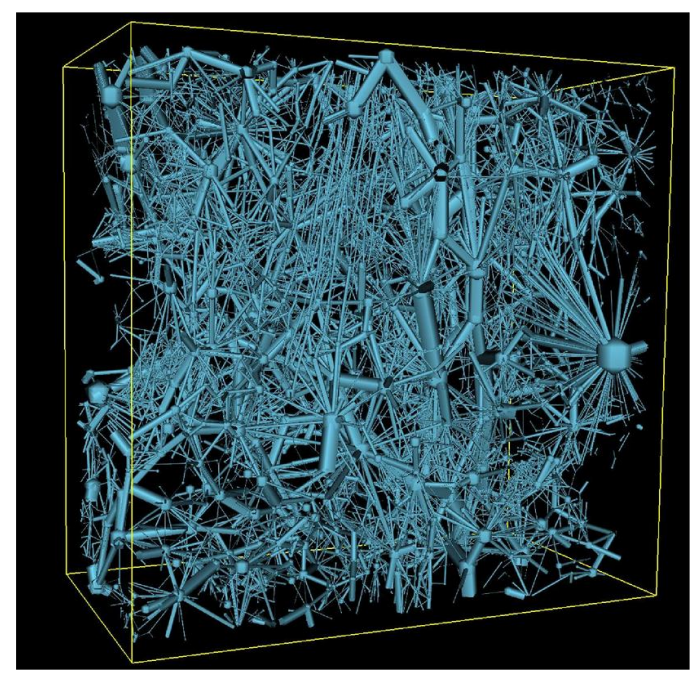

[b]

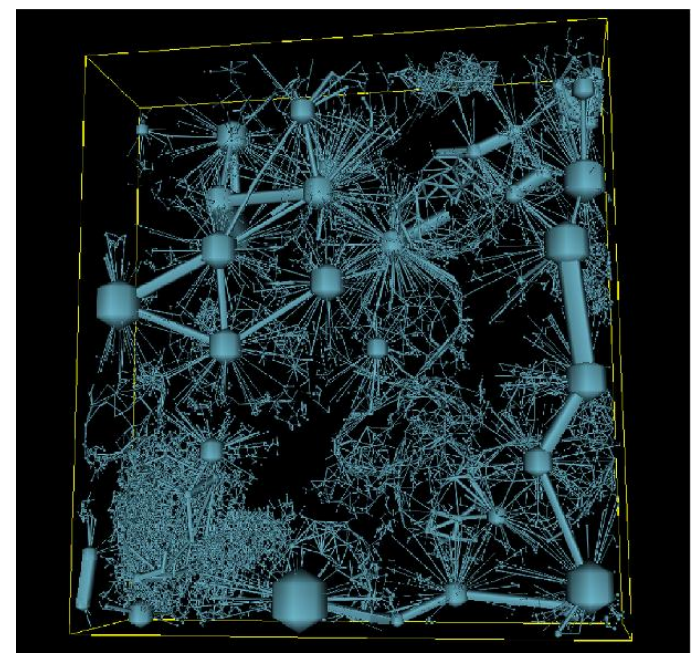

[d]

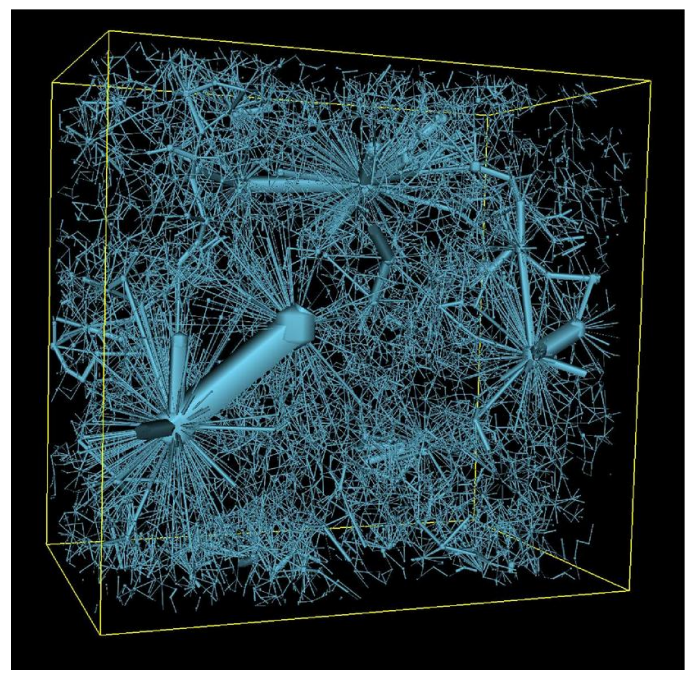

Figure 10. 3D image of subsets of the networks of the (a) "Unconsolidated" (b) "Dual 2", (c) "Outcrop" and (d) "Complex" specimens. The size of the pores and throats reflects their actual size in the partitioning of the tomogram. The variation in structure across the 4 specimens is dramatic. 

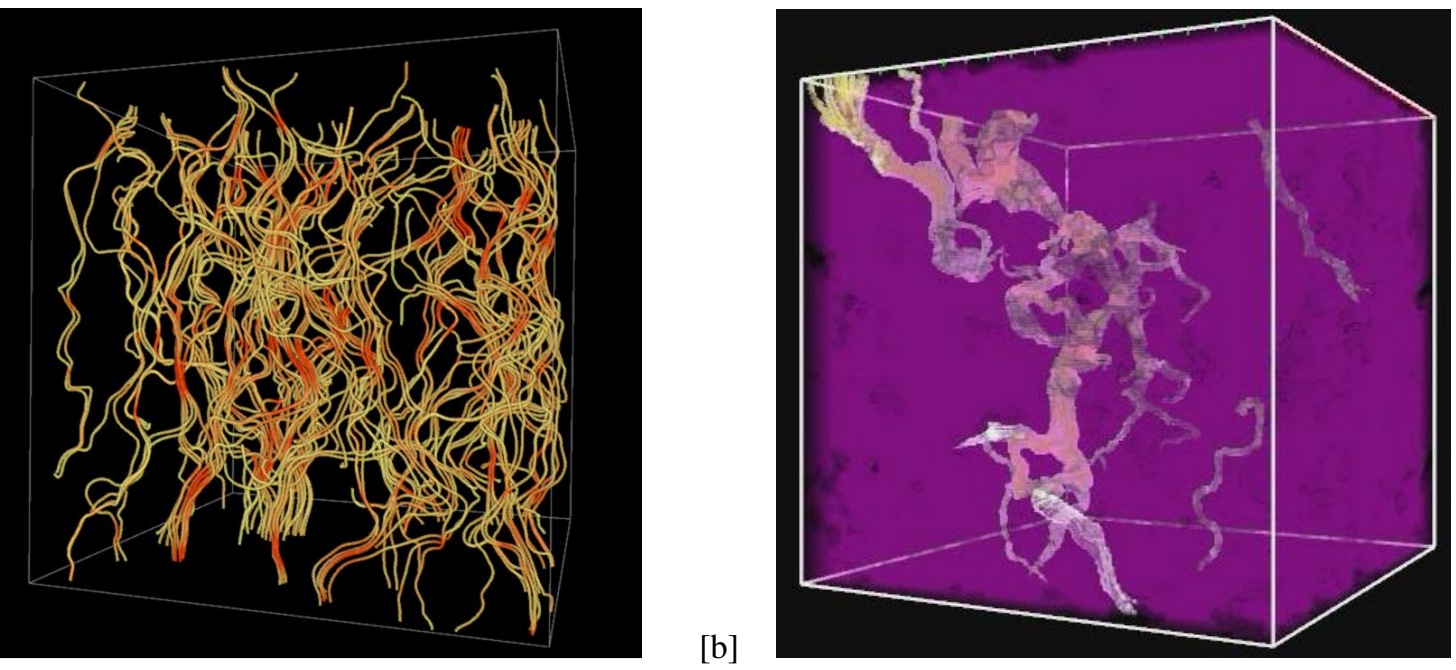

Figure 11. Major flow pathways within the (a) "Consolidated 1" compared to the (b) "Complex" specimen. The latter has a single major flow path, while the former has many equivalent paths.

and analyse materials in 3D in short times and potentially provide materials scientists and engineers with a real-time virtual property testing laboratory for complex porous materials.

\section{ACKNOWLEDGMENTS}

We thank Abid Ghous, Michael Turner and Marios Ioannidis for providing data shown in this paper. The authors gratefully acknowledge fruitful discussions with Val Pinczewski, Stephen Hyde and Tomaso Aste. The authors thank the Australian Research Council (ARC) for support of the hardware development and Australian Partnership for Advanced Computing for funding and generous access to supercomputing resources. The Cooperative Research Centre for Functional Communication Surfaces is also gratefully acknowledged for financial support. Both Arns and Senden gratefully acknowledge the ARC for their fellowships.

\section{REFERENCES}

1. A. Sakellariou, T. J. Sawkins, T. J. Senden, and A. Limaye, "X-ray tomography for mesoscale physics applications," Physica A 339, pp. 152-158, 2004.

2. A. Sakellariou, T. J. Senden, T. J. Sawkins, M. A. Knackstedt, M. L. Turner, A. C. Jones, M. Saadatfar, R. J. Roberts, A. Limaye, C. H. Arns, A. P. Sheppard, and R. M. Sok, "An X-ray tomography facility for a wide range of mesoscale physics applications," in Developments in X-Ray Tomography IV, U. Bonse, ed., Proceedings of SPIE Vol. 5535, pp. 473-484, SPIE, (Bellingham, WA), 2004.

3. L. A. Feldkamp, L. C. Davis, and J. W. Kress, "Practical cone-beam algorithm," J. Opt. Soc. Am. A 1, pp. 612-619, 1984.

4. A. P. Sheppard, R. M. Sok, and H. Averdunk, "Techniques for image enhancement and segmentation of tomographic images of porous materials," Physica A 339, pp. 145-151, 2004.

5. P. Perona and J. Malik, "Scale-space and edge-detection using anisotropic diffusion," IEEE Trans. Pattern Anal. Mach. Intell. 12, pp. 629-639, 1990.

6. W. K. Pratt, Digital Image Processing, John Wiley and Sons, New York, 2nd Ed, 1991.

7. L. Vincent and P. Soille, "Watersheds in digital spaces - an efficient algorithm based on immersion," IEEE Trans. Pattern Anal. Machine. Intell. 13, pp. 583-598, 1991.

8. V. Caselles, R. Kimmel, and G. Shapiro, "Geodesic active contours," Int. J. Comput. Vis. 22, pp. 61-79, 1997.

9. M. Hilpert and C. T. Miller, "Pore-morphology based simulation of drainage in totally wetting porous media," Advances in Water Resources 24, pp. 243-255, 2001. 
10. M. E. Coles, R. D. Hazlett, E. L. Muegge, K. W. Jones, B. Andrews, B. Dowd, P. Siddons, A. Peskin, P. Spanne, and W. E. Soll, "Developments in synchrotron x-ray microtomography with applications to flow in porous media," SPE Reservoir Evaluation and Engineering 36531, pp. 288-296, 1998.

11. C. H. Arns, M. A. Knackstedt, and N. Martys, "Cross-property correlations and permeability estimation in sandstone," Phys. Rev. E 72, p. 046304, 2005.

12. T. Saito and J.-I. Toriwaki, "New algorithms for euclidean distance transformation of an n-dimensional digitized picture with applications," Pattern Recognition 27(11), pp. 1551-1565, 1994.

13. H. Blatt, G. Middleton, and R. Murray, Origin of sedimentary rocks, Prentice-Hall, Englewood Cliffs, N.J., 1972.

14. T. A. Kettler, J. W. Doran, and T. L. Gilbert, "Simplified method for soil particle-size determination to accompany soil-quality analyses," Soil Science Society of America Journal 65, pp. 849-852, 2001.

15. G. W. Gee and J. W. Bauders, Methods of soil analysis, vol. Part 1, Springer-Verlag, $2^{\text {nd }}$ ed., 1986.

16. L. Beuselinck, G. Govers, J. Poesen, G. Degraer, and L. Froyen, "Grain-size analysis by laser diffractometry: comparison with the siev-pipette method," Catena 32, pp. 193-208, 1998.

17. K. Thompson, C. Willson, C. White, S. Nyman, J. Bhattacharya, and A. Reed, "Application of a new grain-based reconstruction algorithm to microtomography images for quantitative characterization and flow modeling," in Annual Technical Conference and Exhibition, SPE 95887, (Dallas, TX), 9-12 October 2005.

18. M. Saadatfar, M. L. Turner, C. H. Arns, H. Averdunk, T. J. Senden, A. P. Sheppard, R. M. Sok, W. V. Pinczewski, J. Kelly, and M. Knackstedt, "Rock fabric and texture from digital core analysis," in Transactions of the SPWLA $46^{\text {th }}$ Annual Logging Symposium, pp. ZZ1-16, Society of Professional Well Log Analysts, (New Orleans, Louisiana, USA), June 2005.

19. A. P. Sheppard, R. M. Sok, and H. Averdunk, "Improved pore-network extraction methods," in $19^{\text {th }}$ International Symposium of the Society of Core Analysts, SCA2005-P89, Society of Core Analysts, (Toronto, Canada), August 262005.

20. V. H. Nguyen, A. P. Sheppard, M. A. Knackstedt, and W. V. Pinczewski, "A dynamic network model for film flow and snap-off in imbibition displacements," J. Petroleum Science and Engineering 52, pp. 54-70, 2006.

21. C. H. Arns, M. A. Knackstedt, W. V. Pinczewski, and N. Martys, "Virtual permeametry on microtomographic images," J. Petroleum Sci. and Eng. 45, pp. 41-46, 2004.

22. C. H. Arns, M. A. Knackstedt, W. V. Pinczewski, and W. B. Lindquist, "Accurate computation of transport properties from microtomographic images," Geophysical Research Letters 28, pp. 3361-3364, 2001.

23. M. A. Knackstedt, C. H. Arns, T. J. Senden, and K. Gross, "Measurement of the 3d structure of coral implants via micro-ct," Biomaterials 27, pp. 2776-2786, 2006.

24. C. H. Arns, M. A. Knackstedt, W. V. Pinczewski, and E. G. Garboczi, "Computation of linear elastic properties from microtomographic images: Methodology and agreement between theory and experiment," Geophysics 67, pp. 1396$1405,2002$.

25. M. A. Knackstedt, C. H. Arns, A. Ghous, A. Sakellariou, T. J. Senden, A. P. Sheppard, R. M. Sok, V. Nguyen, and W. V. Pinczewski, "3d imaging and characterization of the pore space of carbonate core; implications to single and two phase flow properties," in Transactions of the SPWLA $47^{\text {th }}$ Annual Logging Symposium, Society of Professional Well Log Analysts, (New Orleans, Louisiana, USA), June 4-7 2006.

26. M. A. Knackstedt, C. H. Arns, M. Saadatfar, T. J. Senden, A. Sakellariou, A. P. Sheppard, R. M. Sok, W. Schrof, and H. Steininger, "Virtual materials design: Properties of cellular solids derived from 3d tomographic images," Advanced Engineering Materials 7, pp. 238-243, 2005. 